\title{
Editorial
}

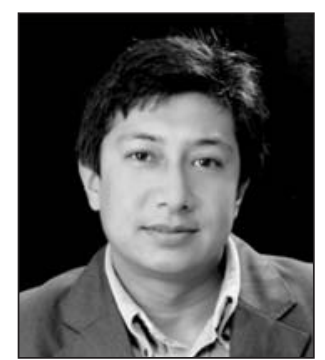

Dr. Rabindra Man Shrestha Chief Editor

\section{NEPALESE HISTORY OF ORTHODONTICS}

The history does not just happen it has to be made. The events that happen today become history in days to come when such events carry impact on the society and memories in the thoughts of the individual. The Nepalese history of Orthodontics is synonymous with the history of Dentistry in Nepal ${ }^{1}$; however it is remote from the world history of Orthodontics ${ }^{2}$ in terms of its involvement and participation in innovations, technology and research.

The practice of Orthodontics is relatively new in Nepal. The first Orthodontic specialist was Dr. Shambhu Man Singh; who completed his Fellowship Diploma from Royal College, Edinburg. He started specialized orthodontic practice in Nepal in 1990. Before this time, orthodontic service was provided by few general dentists limited to removable and functional appliances. It has been reported that, Dr. Khosla from Lucknow used to visit regularly to private clinic in Kathmandu for regular orthodontic service during late 80 's. On the other hand, Dr. Ravindra Nanda used to treat then late Crown Prince Birendra for orthodontic treatment during early 60 's. ${ }^{3}$ And, many orthodontic patients from the elite families of Nepal used to visit Delhi and neighbouring cities of India for Orthodontic treatment.

Then came the era of coming up of qualified Orthodontists with Masteral Degree. Among this league, Dr. Praveen Mishra was the first Nepalese Orthodontist graduated from Manipal, India in 1996 under WHO fellowship. Then after, by the year 2002 onwards few more Orthodontists have started graduating every year from the foreign countries like India, Philippines, Russia, Sri Lanka and China. Dr. Situ Lal Shrestha in 2005 became the first Orthodontist with PhD in Orthodontics. At present there are about twenty five qualified Orthodontists in Nepal. ${ }^{4}$ There is a provision for registration of specialized degree by Nepal Medical Council.

About the orthodontic education in Nepal, People's Dental College, Kathmandu affiliated to Tribhuvan University was the first dental college established in 1997 and subsequently B.P. Koirala Institute of Health Sciences, Dharan started College of Dentistry in 1998. In 2007, Kathmandu University started BDS program through the affiliated Kantipur Dental College. All of these universities conducting BDS program have undergraduate Orthodontic syllabus in their curriculum. The post graduate education in Nepal is of 3-years duration and is awarded MDS (Orthodontics) degree. National Academy of Medical Sciences (NAMS), Bir Hospital, Kathmandu started MDS (Orthodontics) program in 2008; recently first batch of graduates have graduated from NAMS. In 2010, Institute of Medicine, TUTH and People's Dental College; and in 2011 Universal College of Medical Sciences College of Dental Surgery, Bhairahawa started MDS program in Orthodontics.

Orthodontics in Nepal became more organized when the pioneer Orthodontists established 'Orthodontic \& Dentofacial Orthopedic Association of Nepal, ODOAN' in 2007 with an aim to uplift Orthodontic service and practice in Nepal, to increase awareness of orthodontic service and related dentofacial anomalies, and to work for the rights of the Orthodontic professionals. It is registered with District Administration Office, Kathmandu; and is probably the first registered dental speciality organization of Nepal. ODOAN acquired membership of World Federation of Orthodontists (WFO) and Asia Pacific Orthodontic Society (APOS) in 2008. ODOAN was represented in SAARC Orthodontic Conference held in Delhi in 2009.

ODOAN organized First National Orthodontic Conference of Nepal on May 17, 2008 in Kathmandu. Besides the national speakers; invited speaker Prof. Vivek Soni from Mumbai delivered lecture during the scientific session. Now in 2011, ODOAN in association with Pierre Fauchard Academy, India Section is organizing Joint Scientific Orthodontic \& Inter-disciplinary Conference on November 15-16, 2011 at Dhulikhel. ODOAN starts publishing scientific journal 'Orthodontic Journal of Nepal' from 2011.

The Orthodontic service in Nepal is focussed in the capital city Kathmandu and few major cities including Pokhara, Biratnagar, Dharan, Birgunj, Bharatpur, Dhulikhel, Bhairahawa. Many dental hospitals and clinic started extension of Orthodontic service in Kathmandu and dental colleges have the provision of Department of Orthodontics. The Orthodontic practice with most of the Orthodontists is very successful and exclusive with innovative services. The Orthodontic Center, Kathmandu established in 1998 was the first exclusive Orthodontic clinic in Kathmandu. Orthodontic mini implant was used in Nepal for the first time in 2006 by Dr. Rabindra Man Shrestha ${ }^{5}$, and Lingual Orthodontics being practiced for the first time in Nepal by Dr. Dasrath Kafle in 2011.

The Orthodontics is often looked as different and isolated from the main stream general dental practice but Orthodontists have been pioneer and in active involvement with general dental service, government health service, bureaucracy, advocacy, academics, research and management. Nepalese Orthodontists' contribution to the activities of Nepal Dental Association, publication of Nepalese dental journals, representation in Nepal Medical Council and many social services witness the glorious collective Nepalese Dental and Orthodontic efforts to uplift the Dentistry in Nepal. 